\title{
Progressive Decline in Xylem Inflow into Developing Plums
}

\author{
Bishnu P. Khanal, Indu Acharya, and Moritz Knoche \\ Institute of Horticultural Production Systems, Fruit Science Section, Leibniz \\ University Hannover, Herrenhäuser Straße 2, 30419 Hannover, Germany
}

Additional index words. European plum, Prunus $\times$ domestica, xylem, water inflow, transpiration, osmotic pull

\begin{abstract}
Recent evidence suggests xylem functionality may decline in developing European plums. Loss of xylem function may have negative consequences for fruit quality. The aim of this study was to establish and localize the loss of xylem functionality, both spatially and temporally using detached fruit. Fruit were detached from the tree under water and fed through a capillary mounted on the cut end of the pedicel. The rate of water movement through the capillary was recorded. Fruit were held above dry silica gel $[\approx 0 \%$ relative humidity $(\mathrm{RH})]$ or above water $(\approx 100 \% \mathrm{RH})$ to maximize or minimize transpiration, respectively. Water inflow rate depended on developmental stage. It increased from stage I to a maximum at early stage III and then decreased until maturity. Feeding acid fuchsin to developing fruit revealed a progressive decline in dye distribution. The decline progressed basipetally, from the stylar end toward the stem end. At the mature stage III, only the pedicel/fruit junction was stained. The same pattern was observed in four further plum cultivars at the mature stage III. The inflow into early stage III fruit decreased as the RH increased. In contrast, the inflow was less dependent of RH at the mature stage III. Abrading the fruit skin cuticle had no effect on water inflow during early and mature stage III but did markedly increase fruit transpiration rate. Decreasing the osmotic potential (more concentrated) of the feeding solution decreased the water inflow. Our results indicate a progressive loss of xylem functionality in European plum. Transpiration and osmotic pull are the main drivers of this xylem inflow.
\end{abstract}

European plum is an important fruit crop in northern Europe. The fruit of European plum is a drupe that follows a double sigmoidal growth pattern. Early growth (stage I) occurs by cell division throughout the pericarp. Stage I is followed by a lag phase (stage II) in which the stony endocarp and the embryo develop with little change in fruit mass. The final growth phase (stage III or "final swell") is characterized by a rapid increase in mass primarily due to cell expansion in the mesocarp (Lilleland, 1933; Lilleland and Newsome, 1934; Tukey, 1934). Recent evidence suggests xylem functionality may decline in developing European plums during stage III (Winkler and Knoche, 2021). If so, plums would not be unique in this respect. Similar phenomena have been reported in other fruitcrop species, including grapes (Düring et al., 1987; Findlay et al., 1987; Knipfer et al., 2015), kiwifruit (Dichio et al., 2003;

Received for publication 21 May 2021. Accepted for publication 21 July 2021.

Published online 7 September 2021

This research was funded by grant $\mathrm{KN}$ 402/20-1 from the Deutsche Forschungsgemeinschaft. The publication of this article was funded by the Open Access Fund of Leibniz Universität Hannover. We thank Dr. Alexander Lang and Dr. Andreas Winkler for helpful comments on an earlier version of this manuscript.

M.K. is the corresponding author. E-mail: moritz.knoche@obst.uni-hannover.de.

This is an open access article distributed under the CC BY-NC-ND license (https://creativecommons. org/licenses/by-nc-nd/4.0/)
Mazzeo et al., 2013), sweet cherries (Brüggenwirth et al., 2016; Winkler et al., 2016), apples (Drazeta et al., 2004), pear (Morandi et al., 2014), and mango (Nordey et al., 2015).

The reason for the loss of xylem functionality differs among species. In sweet cherry (Grimm et al., 2017) and apple (Drazeta et al., 2004), the loss of xylem functionality is due to rupture of the vessels. In grape, different reasons have been identified including blockages in the lumen of vessels (Knipfer et al., 2015), rupture in the wall of tracheary elements (Düring et al., 1987; Findlay et al., 1987), or a lack of driving force for xylem transport as a result of solute accumulation in the apoplast (Keller et al., 2006, 2015). The decrease in xylem flow in mature mango is caused by embolism in the pedicel xylem and, subsequently, a decrease in hydraulic conductivity (Nordey et al., 2015). A loss of xylem function implies reduced water inflow and, hence, reduced $\mathrm{Ca}$ inflow into the fruit. Both effects have negative consequences for fruit quality. A lack of water inflow contributes to a loss of turgescence that, in extreme cases, may lead to shrivel (Rogiers et al., 2004). Reduced $\mathrm{Ca}$ inflow decreases the cross-linking of cell wall constituents (Caffall and Mohnen, 2009), thereby causing decreased cell-to-cell adhesion and, possibly, increased skin cracking (Winkler and Knoche, 2019; Yu et al., 2020).

The objective of the present study was 1) to confirm the loss of xylem functionality in developing European plums and 2) to localize where in the fruit the xylem loses functionality.

\section{Plant material}

Fruits of European plum (Prunus $\times$ domestica L.) cultivars Hauszwetsche Wolff, Aprimira, Cacaks Schöne, and Toptaste were sampled from the experimental orchard of the Leibniz University at Ruthe, Germany (lat $52^{\circ} 14^{\prime} \mathrm{N}$, long. $9^{\circ} 49^{\prime} \mathrm{E}$ ). Fruit of cultivar Doppelte Hauszwetsche was obtained from an orchard of the Leibniz University in Hannover, Germany (lat. $52^{\circ} 24^{\prime} \mathrm{N}$, long. $9^{\circ} 42^{\prime} \mathrm{E}$ ). Fruits were sampled randomly, detached from the tree and transferred to the laboratories. Only fruit of uniform size and free from visual defects was used.

\section{General experimental procedure}

Measurement of mass, osmotic potential, and hue angle of surface color of the fruit. Fruit were harvested, the pedicel was removed, and mass was quantified on a digital balance (CPA225D; Sartorius, Göttingen, Germany). The surface color of the fruit was measured in the CIE $1976\left(L^{*}, a^{*}\right.$, and $\left.b^{*}\right)$ color space using a spectrophotometer (CM2600d; Konica Minolta, Tokyo, Japan) (McGuire, 1992) and the hue angle was calculated from $a^{*}$ and $b^{*}$ values according to McLellan et al. (1995). The $L^{*}, a^{*}$, and $b^{*}$ values represent the lightness coefficient, the coordinate on the red-green axis, and the coordinate on the yellow-blue axis, respectively. To measure fruit osmotic potential $\left(\Psi_{\pi}\right)$, fruit was sectioned into half, the stone removed, and juice was extracted using a garlic press. Then, the $\Psi_{\pi}$ of the expressed juice was quantified using a vapor pressure osmometer (VAPRO 5520; Wescor, Logan, UT). The number of individual fruit replicates was 30,30 , and 10 for determinations of mass, color, and the $\Psi_{\pi}$.

Potometric measurement of xylem inflow. Water uptake through the pedicel into the fruit via the xylem was quantified using a potometer (Hovland and Sekse, 2004a, 2004b; Knoche et al., 2015). Fruit was harvested (between 7 AM and 2 PM, which varied among the experiments) by cutting the pedicel under water to avoid air embolism and promptly transported (under water) to the nearby laboratory, where the pedicel was recut under water to $\approx 10 \mathrm{~mm}$ length using a razor blade. A 50-mm-long piece of polythene (PE) tubing (1.6-mm inner diameter) filled with deionized water was connected to the pedicel. Fruit were then removed from the water and the tubing/pedicel junction sealed using fast-curing epoxy glue (UHU plus schnellfest, Bühl/Baden, Germany). Fruit were transferred to a PE-box and the tubing attached to the pedicel was guided through a port in the side of the box. To maximize transpiration, the fruit in the PE boxes were then covered with dry silica gel $(\approx 0 \%$ $\mathrm{RH})$. To minimize transpiration, fruit were wrapped in moist tissue paper, enveloped in aluminum foil, and incubated above water $(\approx 100 \% \mathrm{RH})$. The boxes were then closed with a tight-fitting lid in both RH treatments. The PE tubing was connected to a graduated 
capillary comprising a 600 -mm-long piece of Teflon tubing $(0.5-\mathrm{mm}$ inner diameter) mounted next to a ruler. The capillary was filled with $0.01 \%$ aqueous methylene blue to increase contrast for ease of visibility. Earlier studies established there was no difference in potometric flow between deionized water and $0.01 \%$ aqueous methylene blue (Winkler et al., 2016). In this setup, the fruit takes up water via the xylem of the pedicel and the meniscus in the capillary travels toward the fruit. The position of the meniscus was recorded every $30 \mathrm{~min}$ for up to $2 \mathrm{~h}$ unless specified otherwise. The volume of water $\left(\mathrm{mm}^{3}\right.$ or $\left.\mu \mathrm{L}\right)$ taken up by the fruit was calculated by multiplying the distance $(\mathrm{mm})$ of travel by the meniscus in the capillary by the inner cross-sectional area of the capillary $\left(\mathrm{mm}^{2}\right)$. Finally, the rate of water inflow was calculated from the slope of a plot of cumulative water inflow vs. time.

Monitoring xylem functionality by feeding acid fuchsin. Visual evidence for decreased inflow via the xylem during development has been obtained by feeding fruit via the pedicel with a solution containing the apoplastic tracer acid fuchsin. Fruit was harvested randomly (one to two fruit per tree; before 9:00 AM) by cutting pedicels under water as described earlier. A water-filled PE tube was connected to the pedicel stub and the pedicel/tubing junction sealed as described earlier. Thereafter, the water in the tube was replaced by $80 \mu \mathrm{L}$ of $0.1 \%$ aqueous acid fuchsin. Fruit were either incubated at $\approx 0 \% \mathrm{RH}$ or $\approx 100 \% \mathrm{RH}$ for $\approx 6 \mathrm{~h}$. Over this time period, young fruit (but not mature fruit) had taken up the entire volume of tracer. After termination of the feeding period, fruit were removed from the incubation box and the PE tube detached from the pedicel. Fruit were then sectioned using a razor blade. Calibrated photographs were taken using a camera (EOS 550D, lens EF-S $60 \mathrm{~mm} \mathrm{f} / 2.8$ Macro USM; Canon, Tokyo, Japan) on a macrostand. The distribution of tracer in the fruit was monitored during development at 55, 64, 77, 90, $103,125,141$, and $151 \mathrm{~d}$ after full bloom (DAFB) in 'Hauszwetsche Wolff' and at maturity in 'Aprimira' (134 DAFB), 'Cacaks Schöne' (119 DAFB), 'Doppelte Hauszwetsche' (145 DAFB) and 'Toptaste' (129 DAFB).

Fruit transpiration. Fruit transpiration was also quantified on the same batch of fruit as that used in the potometer experiment where the effect of RH on water inflow was quantified. The pedicels were cut to a length of 5 $\mathrm{mm}$. The cut surface of the pedicel was sealed with silicone rubber (Dowsil SE 9186 Clear Sealant; Dow Toray, Tokyo, Japan). After curing, fruit were incubated in PE boxes above dry silica gel or above deionized water and the mass of the fruit recorded after $0,2,4$, and $6 \mathrm{~h}$. A linear regression was fitted through a plot of cumulative water loss $(\mathrm{g})$ vs. time (h). The slope of the regression line represents the rate of transpiration $\left(\mathrm{g} \cdot \mathrm{h}^{-1}\right)$.

\section{Experiments}

Time courses of water uptake via the pedicel were monitored in 'Hauszwetsche Wolff' at early stage II (61 DAFB) and at the mature stage III (146 DAFB). Fruit were connected to a potometer and incubated at $\approx 100 \% \mathrm{RH}$. The position of the meniscus was recorded at 30-min intervals for 8-h and at 24-h intervals for $7 \mathrm{~d}$. The capillary was topped up as necessary. The number of replicates was 11 for 61 DAFB and 12 for 146 DAFB.

The inflow of water and the distribution of the acid fuchsin tracer were quantified at seven intervals of development in 'Hauszwetsche Wolff' plum. These intervals ranged from the end of stage I (55 DAFB) to the fully mature stage III at 151 DAFB. Fruits were incubated at $\approx 0 \%$ or at $\approx 100 \%$ RH. The number of replicates was 12 to 15 for inflow determinations and 10 for monitoring the acid fuchsin distribution.

The inflow of water and the distribution of the acid fuchsin tracer were quantified in mature 'Aprimira' (134 DAFB), 'Cacaks Schöne' (119 DAFB), 'Doppelte Hauszwetsche' (145 DAFB), and 'Toptaste' fruit (129 DAFB). The inflow was determined at $\approx 0 \%$ or at $\approx 100 \%$ RH. The number of replicates was 12 to 15 for the determinations of inflow and 10 for monitoring the acid fuchsin distribution.

To localize the region in the fruit where the xylem may be interrupted, slices (slice thickness was $\approx 25 \%$ of fruit length) were cut off the fruit, starting from the stylar end (distal). The treatments were $0 \%$ (control; fruit remained intact without excision, position 1), $25 \%(25 \%$ of the stylar scar end removed, position 2), $50 \%$ (fruit cut in equatorial plane and the distal 50\% removed, position 3), 75\% (the distal $75 \%$ removed, position 4 ), or $100 \%$ of the fruit removed (only the pedicel used, position 5, see diagram, Fig. 5A). The entire cut surface of the fruit was sealed with silicone rubber (Dowsil SE 9186 Clear Sealant, Dow Toray) and the rates of water inflow quantified as described above. The experiments were carried out using mid stage III (109 DAFB) and mature stage III (149 DAFB) 'Hauszwetsche Wolff'. Here, the number of replicates was 10 to 12 . Because the pit of immature fruit does not separate easily from the flesh, all experiments (at early stage III and mature stage III) were carried out with the pit in the fruit. Thus, the role of the pit was unknown. To establish whether the pit has an effect on the flow rate, the following experiment was conducted using mature (154 DAFB) 'Hauszwetsche Wolff' plum: 1) whole (uncut) fruit, 2) distal $50 \%$ of the flesh removed, 3 ) distal $50 \%$ of the flesh, and $50 \%$ of the pit removed, and 4) distal $50 \%$ of the flesh and $100 \%$ of the pit removed (see diagram, Fig. $6 \mathrm{~A})$. The inflow was quantified as described earlier. The number of replicates was 10 .

The effect of manipulating transpiration on xylem inflow was investigated by changing fruit transpiration in three ways. First, the effect of the RH on the xylem inflow rates in early stage III (94 DAFB) and mature stage III (139 DAFB) 'Hauszwetsche Wolff' plum was established by incubating fruit above dry silica gel $(\approx 0 \% \mathrm{RH})$ or above saturated slurries of calcium chloride $(\approx 25 \% \mathrm{RH}$; Wexler, 1995 ), sodium chloride ( $\approx 75 \% \mathrm{RH}$; Wexler,
$1995)$, or above deionized water $(\approx 100 \%$ $\mathrm{RH})$. The rate of water inflow was determined as described earlier. The rate of transpiration was also quantified on a separate set of fruit from the same batch. The number of replicates was 12 for the determination of water inflow and 15 for the measurement of transpiration.

Second, the effect of submerging fruit in water on inflow into early stage III (90 DAFB) and fully mature stage III (146 DAFB) 'Hauszwetsche Wolff' was quantified. Fruit incubated above dry silica gel $(\approx 0 \% \mathrm{RH})$ or above deionized water $(\approx 100 \% \mathrm{RH})$ served as controls. The number of replicates was 10 to 14 .

In the third approach, to address the role of transpiration on xylem transport, the effect of abrading the cuticle using abrasive paper (P600, $25.8 \mu \mathrm{m}$ particle diameter; Bauhaus, Mannheim, Germany) was studied. The inflow of water via the pedicel and the rate of transpiration were determined. Unabraded fruit served as controls. Fruit was incubated at $\approx 0 \%$ or $\approx 100 \% \mathrm{RH}$. The experiment was conducted in early stage III (92 DAFB) and mature stage III (153 DAFB) 'Hauszwetsche Wolff' plum. The number of replicates was 12 to 14 .

To study the effect of the osmotic potential of the feeding solution on potometric flow, 'Hauszwetsche Wolff' fruit was fed using sucrose solutions of different osmotic potential $(0,-1.25,-2.5,-5$, and $-10 \mathrm{MPa})$ at early stage III ( 85 DAFB) and at mature stage III (147 DAFB). The fruit was held at $\approx 100 \% \mathrm{RH}$ to minimize transpiration. The number of replicates was 13 to 15 .

Data are presented as means and standard errors of 10 to 15 replicates where one replicate represented an individual fruit. Where error bars are not shown, they are smaller than the data symbols. Where meaningful, data were analyzed by analysis of variance (ANOVA; Proc ANOVA or generalized linear model) using the statistical software package SAS (version 9.1.3; SAS Institute, Cary, NC) and means were compared using Tukey's Studentized range test $(P<0.05)$.

\section{Results}

Water inflow through the pedicel to early stage II and mature stage III 'Hauszwetsche Wolff' increased with incubation time. In the short term, inflow rate was essentially linear but this rate clearly decreased when measured over longer periods. In early stage II fruit, inflow approached an asymptote after about $80 \mathrm{~h}$. At this time, inflow into mature fruit continued (Fig. 1A and B). After 48 h, all mature fruit used in the experiment had developed macroscopic cracks.

The increase in fruit mass followed the classical pattern of stone fruit development. On the basis of the growth rhythm, the stage I/II transition occurred at around 55 DAFB and the stage II/III transition at $\approx 85$ DAFB (Fig. 2A). Skin color change occurred at about 110 DAFB (Fig. 2B). The increase in mass was paralleled by a decrease in the $\Psi_{\pi}$ of the expressed juice (the concentration increased) (Fig. 2C). The inflow of water via 

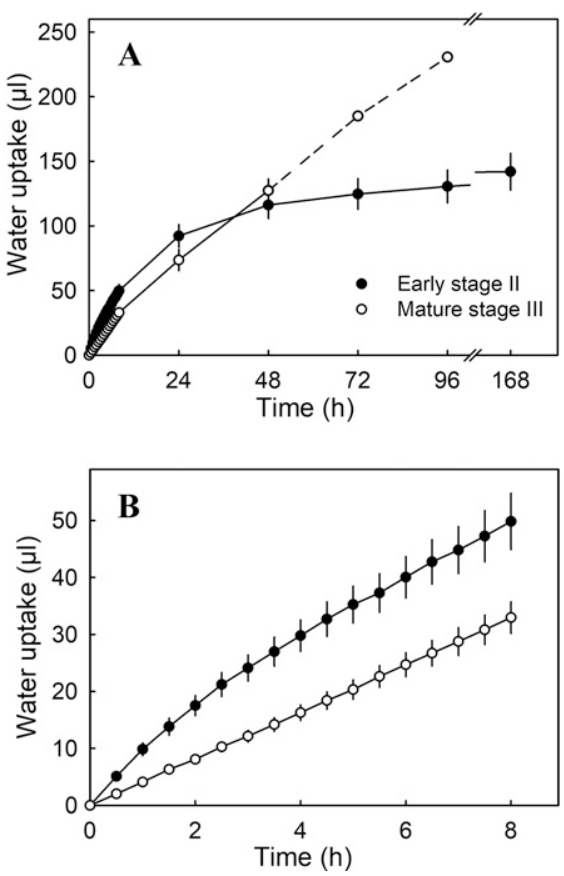

Fig. 1. Time course of water inflow through the xylem of the pedicel of European plum fruit ('Hauszwetsche Wolff') at the early stage II [61 $\mathrm{d}$ after full bloom (DAFB)] and the mature stage III (146 DAFB) (A). (B) Data from 0 to $8 \mathrm{~h}$ of panel A are replotted. The number of replicates was 11 to 12 . Mature fruit had cracked at $\approx 48 \mathrm{~h}$ of incubation. Dashed line represents the inflow into cracked fruit.

the pedicel increased continuously from late stage I until early stage III, then decreased until the mature stage III. The inflow of water into a mature fruit was lower than that into a late stage I fruit. Holding the fruit at $\approx 100 \%$ $\mathrm{RH}$ consistently decreased the inflow as compared with fruit held at $\approx 0 \%$ RH (Fig. 2D).

Feeding acid fuchsin to the pedicel of developing fruit revealed a continuous decline in xylem functionality (Fig. 3). At 55 DAFB, acid fuchsin was observed in the major bundles, the major veins and in most minor veins. The staining of minor veins decreased continuously up to 77 DAFB. By 90 DAFB, no acid fuchsin was found in any of the minor veins. At this time, acid fuchsin was restricted to the median bundles and some major veins. As development continued, dye distribution became more and more restricted to a short portion of the median bundle, close to the pedicel/fruit junction. At 55 and 64 DAFB, fruit held at $\approx 0 \% \mathrm{RH}$ accumulated more dye at the stylar end compared with fruit held at $\approx 100 \%$ RH. From then on, there was little difference in dye distribution between fruit held at $\approx 0$ or at $\approx 100 \%$ RH (Fig. 3 ).

A low rate of inflow into mature European plum was not unique for 'Hauszwetsche Wolff', but was also observed in the other cultivars examined (Table 1). Consistent with the low rate of inflow were the results of feeding mature fruit with acid fuchsin. As in mature stage III 'Hauszwetsche Wolff', inflow was restricted to the proximal region of mature stage III fruit, in the immediate

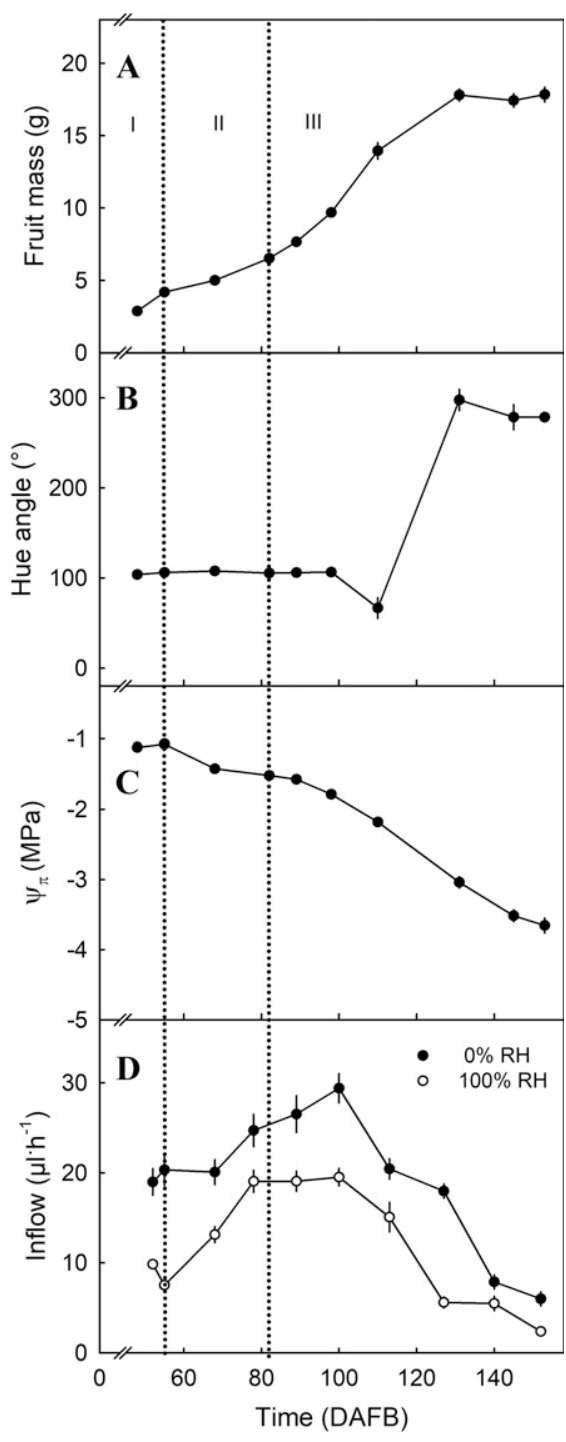

Fig. 2. Time course of change in mass (A), in hue angle of skin color (B), and in osmotic potential $\left(\Psi_{\pi}\right)$ of expressed juice $(\mathbf{C})$ of the fruit of 'Hauszwetsche Wolff' plum. Effect of fruit development on water inflow through the xylem of the fruit pedicel at two levels of relative humidity $(\mathrm{RH})$ (D). Dotted lines represent the transition from stage I to stage II and stage II to stage III of fruit development. The number of replicates was 30 for mass and color, 10 for osmotic potential, and 12 to 15 for water inflow.

vicinity of the pedicel, in the four cultivars examined (Fig. 4).

Further evidence for a progressive loss of xylem functionality was obtained in an experiment, where portions of the fruit were removed beginning at the stylar end. The inflow into mid stage III fruit held at $\approx 0 \%$ $\mathrm{RH}$ decreased as increasing portions of the fruit were excised, beginning at the stylar end. The inflow ceased almost completely when only the pedicel remained connected to the potometer. There was little effect of progressive fruit removal on the inflow into mature stage III fruit. Compared with carrying out the experiment at $\approx 0 \% \mathrm{RH}$, carrying it out at $\approx 100 \% \mathrm{RH}$ produced much the same results but at markedly reduced levels
(Fig. 5). The pit had no effect on water inflow. There were no differences in water inflow among the sections of the fruit with full pit, half pit, or no pit (Fig. 6).

The inflow into early stage III fruit and the rate of transpiration through the skin both decreased as the RH increased (Fig. 7A). At $\approx 100 \% \mathrm{RH}$, transpiration essentially ceased, but significant inflow still occurred via the pedicel.

In mature stage III, the inflow via the pedicel was markedly lower and nearly independent of the external RH, whereas transpiration through the fruit skin increased significantly as RH decreased. The rate of transpiration was higher in mature fruit than in early stage III fruit. As in early stage III fruit, there was no significant transpiration at $\approx 100 \% \mathrm{RH}$ at mature stage III, but there was still a detectable inflow via the pedicel (Fig. 7B).

There was no significant difference in inflow through the pedicel between early stage III fruit held above water or fruit submerged in water (Table 2). The inflow into mature stage III fruit was again markedly reduced and showed little difference among treatments (Table 2).

Abrading the cuticle had no effect on the rate of inflow into either early stage III or mature stage III fruit at either $\approx 0 \%$ or at $\approx 100 \%$ RH (Table 3). Abrasion increased transpiration 8.3 -fold in early stage III and 3.7-fold in mature stage III fruit.

Decreasing the osmotic potential (increasing the osmotic concentration) of the feeding solution, decreased the inflow into early stage III fruit but had less effect in mature stage III fruit (Fig. 8). Similar observations were again obtained when the experiment was repeated in a subsequent season (data not shown). Even when a hypertonic solution (i.e., a solution more concentrated than the fruit's expressed juice) was fed to the pedicel, the inflow continued. When the experiment was conducted using detached pedicels, there was no flow, regardless of the osmotic potential of the solution (data not shown).

\section{Discussion}

In our discussion, we focus on 1) the progressive loss of xylem functionality in developing plums and 2) the driving force for inflow via the pedicel.

No functional xylem in mature European plum. The evidence for the loss of xylem function is based on 1) the marked decrease in xylem inflow despite an increase in fruit mass and, hence, an increase in surface area. The larger fruit surface area will have resulted in higher rates of transpiration which should have increased the xylem inflow. However, the reverse was the case. 2) There is a progressive decrease in vascular staining by the apoplastic tracer acid fuchsin. The dysfunction begins at the fruit's stylar end and progresses basipetally (i.e., toward the pedicel end). The spatial and temporal patterns in loss of xylem function match the decreases in inflow following progressive removal of increasing proportions of the fruit by excision. 3) The xylem 

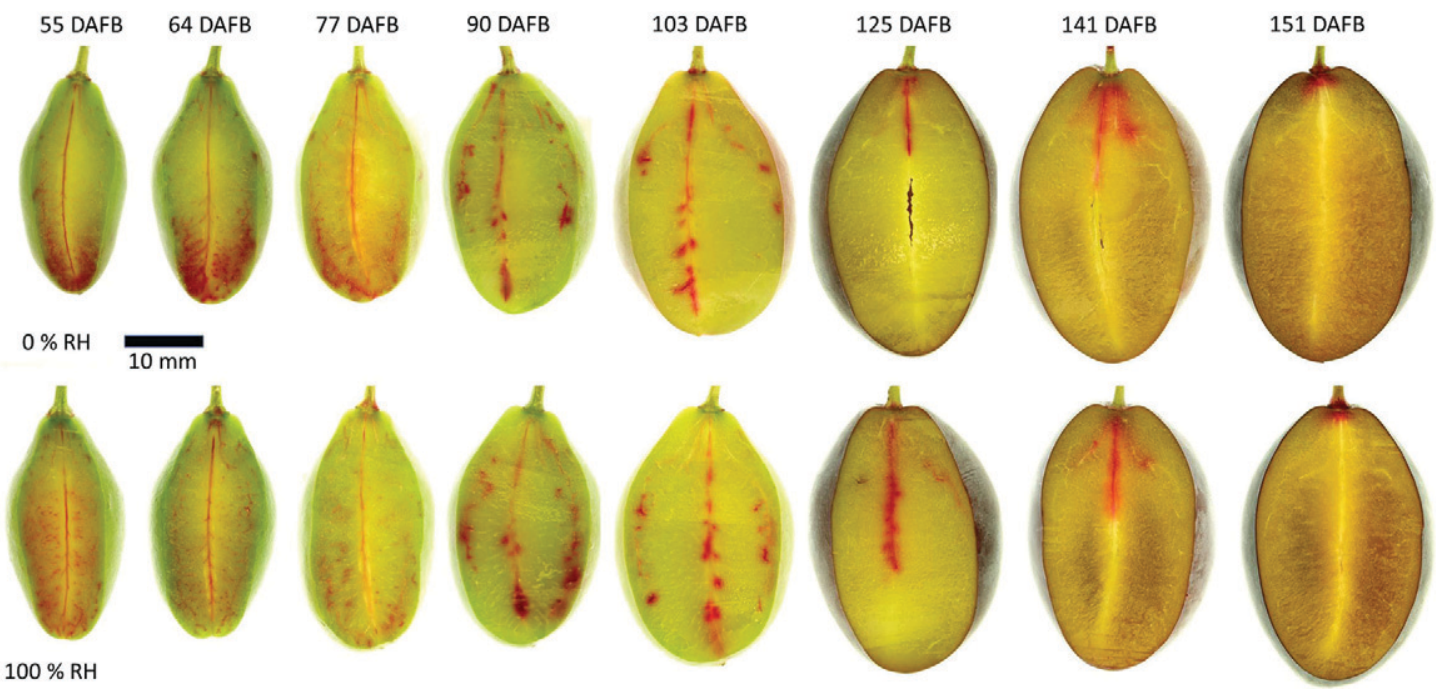

Fig. 3. Developmental time course of the distribution of the tracer acid fuchsin when fed to the pedicel of 'Hauszwetsche Wolff' plum. Fruit was incubated at $\approx 0 \%$ relative humidity $(\mathrm{RH})$ to maximize transpiration or at $\approx 100 \% \mathrm{RH}$ to minimize transpiration. After $5 \mathrm{~h}$ of feeding, the fruit were cut along the pedicel-style axis in the cheek region to expose the median bundle and the cut surface photographed. Numbers above individual images specify the days after full bloom (DAFB). The number of replicates was 10 .

Table 1. Inflow through the xylem to fruit of selected plum cultivars at the mature stage III. Fruit was incubated at $\approx 0 \%$ relative humidity $(\mathrm{RH})$ to maximize transpiration or at $\approx 100 \% \mathrm{RH}$ to minimize transpiration. The number of replicates was 12 to 15 .

\begin{tabular}{lccc}
\hline & \multicolumn{2}{c}{ Inflow $\left(\mu \mathrm{L} \cdot \mathrm{h}^{-1}\right)$} \\
\cline { 3 - 4 } Cultivar & Days after full bloom & $0 \% \mathrm{RH}$ & $100 \% \mathrm{RH}$ \\
\hline Aprimira & 134 & $4.1 \pm 0.4 \mathrm{a}^{\mathrm{z}}$ & $1.8 \pm 0.2 \mathrm{~b}$ \\
Cacaks Schöne & 119 & $7.6 \pm 0.8 \mathrm{a}$ & $4.5 \pm 0.4 \mathrm{~b}$ \\
Doppelte Hauszwetsche & 145 & $10.0 \pm 0.7 \mathrm{a}$ & $4.9 \pm 0.3 \mathrm{~b}$ \\
Hauszwetsche Wolff & 152 & $6.0 \pm 0.8 \mathrm{a}$ & $2.4 \pm 0.2 \mathrm{~b}$ \\
Toptaste & 129 & $3.0 \pm 0.1 \mathrm{a}$ & $1.6 \pm 0.1 \mathrm{~b}$ \\
Mean & & $6.0 \pm 0.4$ & $2.9 \pm 0.2$ \\
\hline
\end{tabular}

${ }^{\mathrm{z}}$ Mean separation within rows by Tukey's Studentized range test at $P \leq 0.05$.
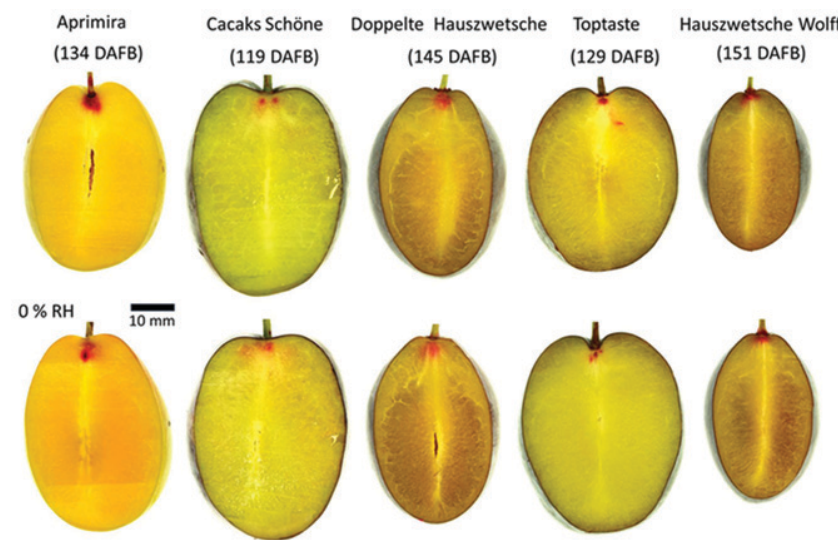

$100 \%$ RH

Fig. 4. Distribution of the tracer acid fuchsin after feeding to the pedicel of 'Aprimira', 'Cacaks Schöne', 'Doppelte Hauszwetsche', 'Hauszwetsche Wolff', or 'Toptaste' plums. Fruit was incubated at $\approx 0 \%$ relative humidity $(\mathrm{RH})$ to maximize transpiration or at $\approx 100 \% \mathrm{RH}$ to minimize transpiration. After $5 \mathrm{~h}$ of feeding, the fruit were cut along the pedicel-style axis in the cheek region to expose the median bundle and the cut surface photographed. The images for 'Hauszwetsche Wolff' plums were taken from Fig. 3. All fruit were at the mature stage III. Days after full bloom (DAFB) are given in parenthesis. The number of replicates was 10 .

inflow in mature fruit becomes independent of transpiration, whereas during early stage III inflow depended on fruit transpiration. These findings are consistent across the five plum cultivars investigated here. The results match earlier observations in European plum obtained using linear variable displacement transducers (LVDTs; Winkler and Knoche, 2021). The reason for the loss of function in European plum is not known.

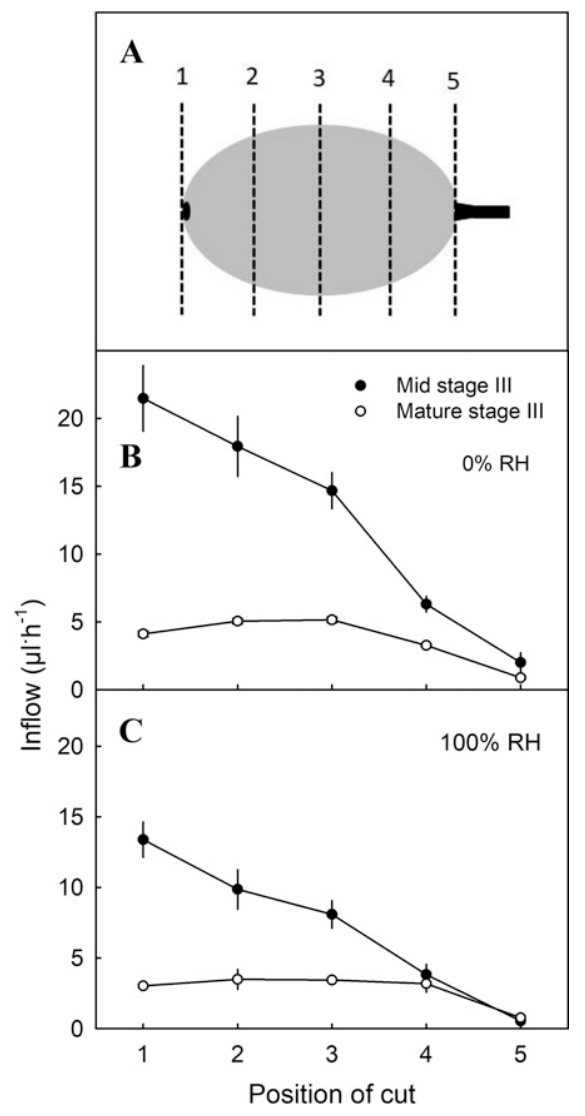

Fig. 5. Effect of progressive removal of the distal portions of the fruit: $0 \%(1), 25 \%(2), 50 \%$ (3), $75 \%(4)$, and $100 \%(5)$ on water inflow through the pedicel of mid stage III [109 d after full bloom (DAFB)] and mature stage III (149 DAFB) fruit of 'Hauszwetsche Wolff' plum. Rates of water inflow were recorded at $\approx 0 \%$ (A) and at $\approx 100 \%$ (B) RH. The number of replicates was 10 to 12 .

Driving force for inflow. The xylem resembles a continuum of tiny, water-filled pipes. The flow through these pipes follows 


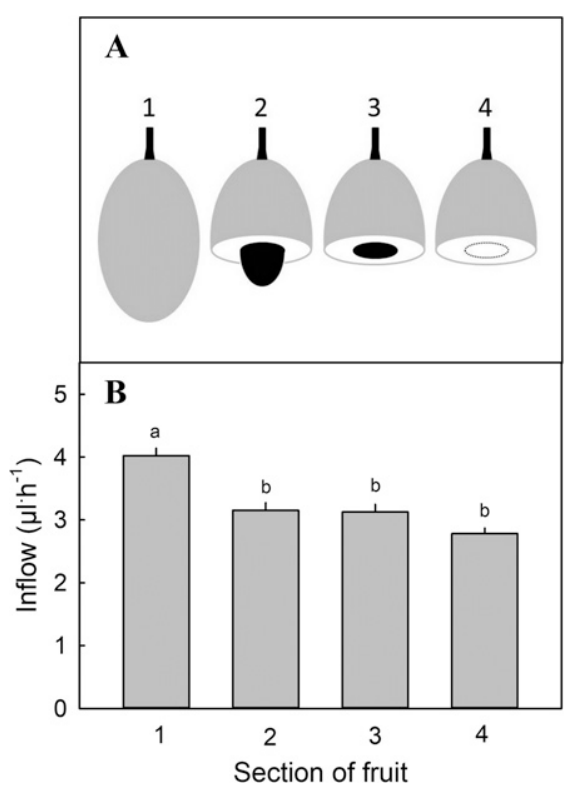

Fig. 6. Effect of the pit on water inflow through the pedicel into the fruit of plum (cv. Hauszwetsche Wolff). (A) Sketch of whole fruit (1), half flesh+full pit (2), half flesh+half pit, (3) and half flesh + no pit (4). Water inflow for all four cut treatments was quantified at $\approx 100 \%$ RH (B) using fruit at the mature stage III [154 d after full bloom (DAFB)]. The number of replicates was 10 .

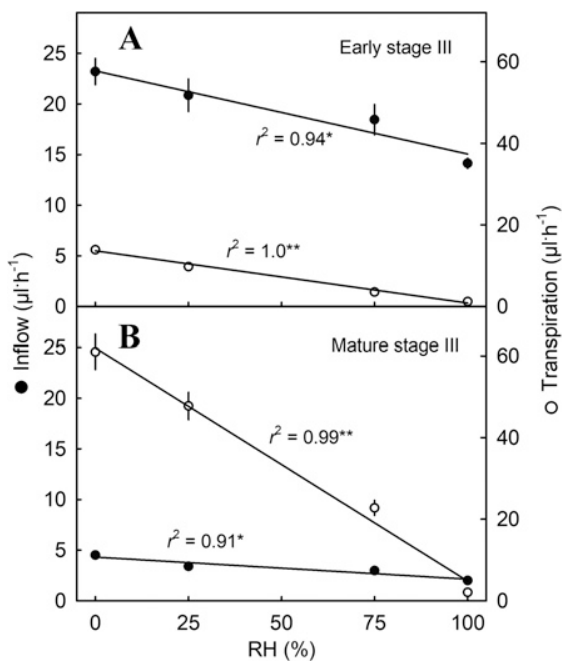

Fig. 7. Effect of relative humidity $(\mathrm{RH})$ on water inflow through the fruit pedicel and on the rate of transpiration through the fruit surface of early stage III (94 d after full bloom; DAFB) (A) and mature stage III (139 DAFB) 'Hauszwetsche Wolff' plums (B). The number of replicates was 12 for water inflow and 15 for transpiration.

Hagen Poiseuille's law. For a given geometry, the flow rate is a function of the pressure gradient along the pipe. This gradient is generated by the transpiration stream that pulls water through the xylem continuum from the roots, up to the transpiring (fruit) surfaces. This argument is supported by 1) a negative relationship between the rate of transpiration and the RH and 2) a consistently higher
Table 2. Effect of incubating fruit at $\approx 0 \%$ or $100 \%$ relative humidity (RH) or of submerging 'Hauszwetsche Wolff' European plums on inflow through the xylem to the fruit Water inflow was quantified at early stage III [90 d after full bloom (DAFB)] and mature stage III (146 DAFB). The number of replicates was 10 to 14 .

\begin{tabular}{lcc}
\hline & \multicolumn{2}{c}{ Inflow $\left(\mu \mathrm{L} \cdot \mathrm{h}^{-1}\right)$} \\
\cline { 2 - 3 } Treatment & Early stage III & Mature stage III \\
\hline $0 \% \mathrm{RH}$ & $24.0 \pm 1.7 \mathrm{a}^{\mathrm{z}}$ & $5.4 \pm 0.2 \mathrm{a}$ \\
$100 \% \mathrm{RH}$ & $18.1 \pm 1.5 \mathrm{~b}$ & $5.5 \pm 0.2 \mathrm{a}$ \\
Submerged & $18.7 \pm 1.4 \mathrm{~b}$ & $4.1 \pm 0.1 \mathrm{~b}$ \\
\hline
\end{tabular}

${ }^{\mathrm{z}}$ Mean separation within columns by Tukey's Studentized range test at $P \leq 0.05$.

inflow rate in all experiments for fruit incubated at $\approx 0 \% \mathrm{RH}$ compared with at $\approx 100 \%$ $\mathrm{RH}$. This is also consistent with other published information (Winkler et al., 2016).

However, transpiration is not the sole factor governing xylem inflow in European plum. 1) Abrasion of the fruit cuticle increased the rate of transpiration 8.3-fold in early stage III fruit and 3.7-fold in mature stage III fruit but had no effect on the inflow via the pedicel. If fruit transpiration were the sole driving force, we would expect the inflow to increase proportionately. 2) Particularly into early stage III fruit, we observed a consistent xylem inflow to the fruit under nontranspiring conditions, both at $\approx 100 \% \mathrm{RH}$ air and when submerged in water. Assuming this inflow to be additive to that resulting from transpiration, this inflow accounted for up to $65 \%$ of the total. Fruit being detached from the tree in all these experiments, this residual inflow component must have been in the xylem because it could not have been in the phloem. 3) Decreasing the osmotic potential (more concentrated) of the feeding solution decreased the rate of inflow. If transpiration was the sole driving force, this residual xylem inflow would be expected to be independent of the osmotic potential of the feeding solution. Similar observations have been reported for sweet cherries (Winkler et al., 2016).

As in sweet cherry, osmotic water movement from the apoplast of the cell wall free space into the symplast may contribute to the driving force in European plum. Such water uptake would generate a supplementary (additive) tension that would draw water from the tree through the xylem into the symplast of the fruit. It would account for inflow in the absence of transpiration and hence is a contributor to the driving force for xylem flow in European plum. An osmotically driven inflow via the xylem may also have contributed to the cracking of mature fruit that was observed in the long-term time course study at $\approx 48 \mathrm{~h}$. In this experiment, the fruit was unable to transpire because it was held at $100 \% \mathrm{RH}$. The inflow into mature fruit apparently was sufficiently high to induce cracking indicating that some part of the xylem must have remained functional. This is consistent with 1) the observation of some residual staining of the proximal end of mature fruit after feeding with acid fuchsin (Figs. 3 and 4 ) and 2) estimates of $\approx 25 \%$ of the inflow into a mature European plum being accounted for by the xylem (Winkler and Knoche, 2021). However, a question remains. A xylem inflow was also recorded when the pedicel was fed with solutions hypertonic relative to the fruits' own expressed juice. At rates of inflow between 10 and $18 \mu \mathrm{L} \cdot \mathrm{h}^{-1}$ and a $10-\mathrm{mm}$ length of pedicel, these hypertonic solutions must have reached the interface between symplast and apoplast. Under these conditions (i.e., a hypertonic xylem sap), osmotic water uptake by the symplast would be impossible. Instead, the symplast would lose water to the apoplast, possibly causing plasmolysis. Such a decrease in cell turgor would now permit cell walls to swell (Schumann and Knoche, 2020). These phenomena occur in sweet cherry and also in a number of other fruitcrop species and could possibly also account for water inflow into European plum fruit.

\section{Conclusion}

Our results indicate plums suffer a progressive loss of xylem functionality similar to that recorded in sweet cherry and in a number of other fruitcrop species. Transpiration and osmotic pull are the two key drivers generating the tension for xylem inflow to the fruit. The progressive decline in xylem functionality implies it becomes increasingly difficult for a plum to import minerals that are mobile only in the xylem sap (e.g., Ca), particularly during stage III. This leaves foliar applications of Ca-salts as the only effective measure to increase the fruits' $\mathrm{Ca}$ content. In addition, a role of xylem inflow in the neck shrivel disorder of European plum becomes unlikely as the loss of functionality progresses from the stylar end to the pedicel end.

Table 3. Effect of abrading the fruit skin cuticle on the inflow through the xylem of the pedicel and on the rate of fruit transpiration of early stage III [92 d after full bloom (DAFB)] and mature stage III (153 $\mathrm{DAFB}$ ) 'Hauszwetsche Wolff' plums. Fruit was incubated at $\approx 0 \%$ relative humidity (RH) to maximize transpiration or at $\approx 100 \% \mathrm{RH}$ to minimize transpiration. The number of replicates was 12 to 14 .

\begin{tabular}{llccccc}
\hline & & \multicolumn{2}{c}{ Flow $\left(\mu \mathrm{L} \cdot \mathrm{h}^{-1}\right)$} & & \multicolumn{2}{c}{ Transpiration $\left(\mu \mathrm{L} \cdot \mathrm{h}^{-1}\right)$} \\
\cline { 3 - 4 } \cline { 7 - 7 } RH (\%) & Treatment & Early stage III & Mature stage III & & Early stage III & Mature stage III \\
\hline 0 & Control & $25.8 \pm 1.1 \mathrm{a}^{\mathrm{z}}$ & $3.5 \pm 0.4 \mathrm{a}$ & & $22 \pm 1 \mathrm{~b}$ & $64 \pm 3 \mathrm{~b}$ \\
& Abraded & $28.6 \pm 1.0 \mathrm{a}$ & $3.5 \pm 0.2 \mathrm{a}$ & & $182 \pm 6 \mathrm{a}$ & $239 \pm 9 \mathrm{a}$ \\
100 & Control & $14.0 \pm 0.5 \mathrm{a}$ & $1.9 \pm 0.1 \mathrm{a}$ & & $1 \pm 0 \mathrm{~b}$ & $2 \pm 0 \mathrm{a}$ \\
& Abraded & $15.1 \pm 0.4 \mathrm{a}$ & $2.0 \pm 0.1 \mathrm{a}$ & & $5 \pm 1 \mathrm{a}$ & $-5 \pm 1 \mathrm{~b}$ \\
\hline
\end{tabular}

${ }^{\mathrm{z}}$ Mean separation within treatments (abrasion) down columns by Tukey's Studentized range test at $P \leq 0.05$ 


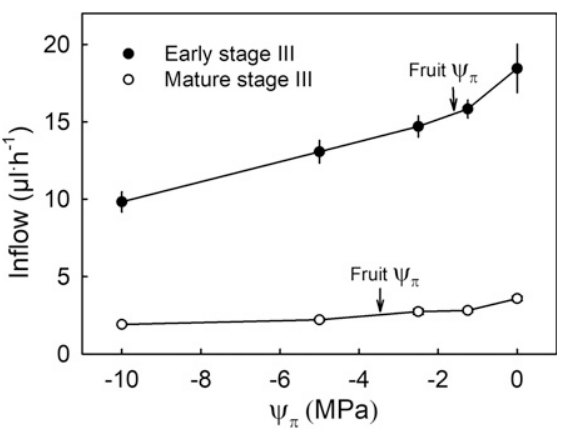

Fig. 8. Effect of the osmotic potential of the feeding solution $\left(\Psi_{\pi}\right)$ on water inflow through the xylem of the pedicel into early stage III [ $85 \mathrm{~d}$ after full bloom (DAFB)] and mature stage III (147 DAFB) 'Hauszwetsche Wolff' plums. The fruit was held under nontranspiring conditions. Arrows indicate the osmotic potential $\left(\Psi_{\pi}\right)$ of expressed juice of the fruit. The number of replicates was 13 to 15 .

\section{Literature Cited}

Brüggenwirth, M., A. Winkler, and M. Knoche. 2016. Xylem, phloem, and transpiration flows in developing sweet cherry fruit. Trees 30 : 1821-1830, doi: 10.1007/s00468-016-1415-4.

Caffall, K.H. and D. Mohnen. 2009. The structure, function, and biosynthesis of plant cell wall pectic polysaccharides. Carbohydr. Res. 344: 1879-1900, doi: 10.1016/j.carres.2009.05.021.

Dichio, B., D. Remorini, and S. Lang. 2003. Developmental changes in xylem functionality in kiwifruit fruit: Implications for fruit calcium accumulation. Acta Hort. 610:191-195, doi: 10.17660/ActaHortic.2003.610.25.

Drazeta, L., A. Lang, A.J. Hall, R.K. Volz, and P.E. Jameson. 2004. Causes and effects of changes in xylem functionality in apple fruit. Ann. Bot. 93:275-282, doi: 10.1093/aob/mch040.

Düring, H., A. Lang, and F. Oggionni. 1987. Patterns of water flow in Riesling berries in relation to developmental changes in their xylem morphology. Vitis 26:123-131, doi: 10.5073/ vitis. 1987.26.123-131.

Findlay, N., K.J. Oliver, N. Nil, and B.G. Coombe. 1987. Solute accumulation by grape pericarp cells: IV. Perfusion of pericarp apoplast via the pedicel and evidence for xylem malfunction in ripening berries. J. Expt. Bot. 38:668-679, doi: 10.1093/jxb/38.4.668.

Grimm, E., D. Pflugfelder, D. van Dusschoten, A. Winkler, and M. Knoche. 2017. Physical rupture of the xylem in developing sweet cherry fruit causes progressive decline in xylem sap inflow rate. Planta 246:659-672, doi: 10.1007/ s00425-017-2719-3.

Hovland, K.L. and L. Sekse. 2004a. Water uptake through sweet cherry (Prunus avium L.) fruit pedicels: Influence of fruit surface water status and intact fruit skin. Acta Agr. Scandinavica Sect. B Soil Plant Sci. 54:91-96, doi: 10.1080/ 09064710410024444.

Hovland, K.L. and L. Sekse. 2004b. Water uptake through sweet cherry (Prunus avium L.) fruit pedicels in relation to fruit development. Acta Agr. Scandinavica. Sect. B Soil Plant Sci. 54:264-266, doi: 10.1080/09064710410035659.

Keller, M., Y. Zhang, P.M. Shrestha, M. Biondi, and B.R. Bondada. 2015. Sugar demand of ripening grape berries leads to recycling of surplus phloem water via the xylem. Plant Cell Environ. 38:1048-1059, doi: 10.1111/pce.12465.

Keller, M., J.P. Smith, and B.R. Bondada. 2006. Ripening grape berries remain hydraulically connected to the shoot. J. Expt. Bot. 57:2577-2587, doi: 10.1093/jxb/erl020.

Knipfer, T., J. Fei, G.A. Gambetta, A.J. McElcone, K.A. Shakel, and M.A. Matthews. 2015. Water transport properties of the grape pedicel during fruit development: Insights into xylem anatomy and function using microtomography. Plant Physiol. 168:1590-1602, doi: 10.1104/pp.15.00031.

Knoche, M., T.O. Athoo, A. Winkler, and M. Brüggenwirth. 2015. Postharvest osmotic dehydration of pedicels of sweet cherry fruit. Postharvest Biol. Technol. 108:86-90, doi: 10.1016/j.postharvbio.2015.05.014.

Lilleland, O. 1933. Growth study of the plum fruit I: The growth and changes in chemical composition of the climax plum. Proc. Am. Soc. Hort. Sci. 30:203-208.

Lilleland, O. and L. Newsome. 1934. A growth study of the cherry fruit. Proc. Amer. Soc. Hort. Sci. 32:291-299.

Mazzeo, M., B. Dichio, M.J. Clearwater, G. Montanaro, and C. Xilioyannis. 2013. Hydraulic resistance of developing Actinidia fruit. Ann. Bot. 112:197-205, doi: 10.1111/j.1755-0238. 2011.00177.x.
McGuire, R.G. 1992. Reporting of objective color measurements. HortScience 27:1254-1255, doi: 10.21273/HORTSCI.27.12.1254.

McLellan, M.R., L.R. Lind, and R.W. Kime. 1995. Hue angle determinations and statistical analysis for multiquadrant hunter $\mathrm{L}, \mathrm{a}, \mathrm{b}$ data. J. Food Qual. 18:235-240, doi: 10.1111/j.17454557.1995.tb00377.x.

Morandi, B., P. Losciale, I. Manfrini, M. Zibordi, S. Anconelli, E. Pierpaoli, and L.C. Grappadelli. 2014. Leaf gas exchanges and water relations affect the daily patterns of fruit growth and vascular flows in Abbé Fétel pear (Pyrus communis L.) trees. Scientia Hort. 178:106-113, doi: 10.1016/j. scienta.2014.08.009.

Nordey, T., M. Léchaudel, and M. Génard. 2015. The decline in xylem flow to mango fruit at the end of its development is related to the appearance of embolism in the fruit pedicel. Funct. Plant Biol. 42:668-675, doi: 10.1071/ FP14306.

Rogiers, S.Y., J.M. Hatfield, V.G. Jaudzems, R.G. White, and M. Keller. 2004. Grape berry cv. Shiraz epicuticular wax and transpiration during ripening and preharvest weight loss. Amer. J. Enol. Viticult. 55:121-127.

Schumann, C. and M. Knoche. 2020. Swelling of cell walls in mature sweet cherry fruit: Factors and mechanisms. Planta 251:65, doi: 10.1007/ s00425-020-03352-y.

Tukey, H.B. 1934. Growth of the embryo, seed, and pericarp of the sour cherry (Prunus cerasus) in relation to season of fruit ripening. Proc. Amer. Soc. Hort. Sci. 31:125-144.

Wexler, A. 1995. Constant humidity solutions, p. 15-23. In: D.R. Lide (ed.). Handbook of chemistry and physics. 76th ed. CRC Press, Boca Raton, FL.

Winkler, A., M. Brüggenwirth, N.S. Ngo, and M. Knoche. 2016. Fruit apoplast tension draws xylem water into mature sweet cherries. Scientia Hort 209:270-278, doi: 10.1016/j.scienta.2016.06.041.

Winkler, A. and M. Knoche. 2019. Calcium and the physiology of sweet cherries: A review. Scientia Hort. 245:107-115, doi: 10.1016/j. scienta.2018.10.012.

Winkler, A. and M. Knoche. 2021. Xylem, phloem and transpiration flows in developing European plums. PLoS One 16:e252085, doi: 10.1371/ journal.pone. 0252085 .

Yu, J., M. Zhu, M. Bai, Y. Xu, S. Fan, and G. Yang. 2020. Effect of calcium on relieving berry cracking in grape (Vitis vinifera L.) 'Xiangfei'. PeerJ 8:e9896, doi: 10.7717/peerj.9896. 